\title{
Impaired ventilatory and thermoregulatory responses to hypoxic stress in newborn Phox $2 b$ heterozygous knock-out mice
}

\author{
Nelina Ramanantsoa ${ }^{1,2}$, Boris Matrot 1,2, Guy Vardon ${ }^{3}$, Anne-Marie Lajard ${ }^{4}$, Nicolas Voituron ${ }^{4}$, \\ Stéphane Dauger ${ }^{1,2,5}$, André Denjean ${ }^{1,2,6}$, Gérard Hilaire ${ }^{4}$ and Jorge Gallego ${ }^{1,2}$ * \\ 1 INSERM, UMR 676, Robert Debré Hospital, Paris, France \\ ${ }^{2}$ Faculty of Medicine, University Denis Diderot, Paris, France \\ ${ }^{3}$ Faculty of Medicine, University of Amiens, Amiens, France \\ ${ }^{4}$ CNRS, UMR 6231, Faculty Saint Jérôme, Research Center of Neurobiology and Neurophysiology of Marseille, University of Aix-Marseille II and III, Marseille, France \\ ${ }^{5}$ Pediatric Intensive Care Unit, AP-HP, Robert Debré Hospital, Paris, France \\ 6 Physiology Department, AP-HP, Robert Debré Hospital, Paris, France
}

\section{Edited by:}

Bill J. Yates, University of Pittsburgh, USA

\section{Reviewed by:}

Bill J. Yates, University of Pittsburgh, USA

Jean-Paul Praud, Université de Sherbrooke, Canada

\section{*Correspondence:}

Jorge Gallego, INSERM U676, Robert Debré Hospital, 48 Boulevard Sérurier, 75019 Paris, France. e-mail: jorge.gallego@inserm.fr
The Phox $2 b$ genesis necessary for the development of the autonomic nervous system, and especially, of respiratory neuronal circuits. In the present study, we examined the role of Phox $2 b$ in ventilatory and thermoregulatory responses to hypoxic stress, which are closely related in the postnatal period. Hypoxic stress was generated by strong thermal stimulus, combined or not with reduced inspired $\mathrm{O}_{2}$. To this end, we exposed 6-dayold Phox $2 b^{+/-}$pups and their wild-type littermates $\left(\right.$Phox $\left.2 b^{+/+}\right)$to hypoxia $\left(10 \% \mathrm{O}_{2}\right)$ or hypercapnia $\left(8 \% \mathrm{CO}_{2}\right)$ under thermoneutral $\left(33^{\circ} \mathrm{C}\right)$ or cold $\left(26^{\circ} \mathrm{C}\right)$ conditions. We found that Phox $2 b^{+/-}$pups showed less normoxic ventilation $\left(V_{E}\right)$ in the cold than Phox $2 b^{+/+}$ pups. Phox $2 b^{+/-}$pups also showed lower oxygen consumption $\left(\mathrm{VO}_{2}\right)$ in the cold, reflecting reduced thermogenesis and a lower body temperature. Furthermore, while the cold depressed ventilatory responses to hypoxia and hypercapnia in both genotype groups, this effect was less pronounced in Phox $2 b^{+/-}$pups. Finally, because serotonin (5-HT) neurons are pivotal to respiratory and thermoregulatory circuits and depend on Phox $2 b$ for their differentiation, we studied 5-HT metabolism using high pressure liquid chromatography, and found that it was altered in Phox $2 b^{+/-}$pups. We conclude that Phox $2 b$ haploinsufficiency alters the ability of newborns to cope with metabolic challenges, possibly due to 5-HT signaling impairments.

Keywords: control of breathing, chemosensitivity, hypoxia, hypercapnia, cold

\section{INTRODUCTION}

The transcription factor Phox $2 b$ is a master regulator of the embryonic development of the autonomic nervous system and, especially, of respiratory circuits (Goridis et al., 2010). Phox $2 b$ is expressed by afferent pathways from $\mathrm{O}_{2}$-sensitive peripheral chemoreceptors, by chemoresponsive projections of the nucleus tractus solitarius to the ventrolateral medulla, and by central chemoreceptors located in the retrotrapezoid nucleus (RTN; Abbott et al., 2009). In humans, mutations in the Phox $2 b$ gene have been determined to cause Congenital Central Hypoventilation Syndrome (CCHS), which is characterized by hypoventilation during sleep and impaired chemosensitivity (Amiel et al., 2009). Knock-in mice harboring Phox $2 b$ mutations identified in CCHS patients display apneas and a lack of responsiveness to hypercapnia, and die soon after birth (Dubreuil et al., 2008). These mice show a specific loss of $\mathrm{CO}_{2}$-sensitive cells in the RTN (Dubreuil et al., 2008). Phox $2 b$ mutant embryos, in which RTN neurons are specifically depleted, display a reduced phrenic burst frequency and an impaired response to acidification (Dubreuil et al., 2009). Newborn mice carrying one invalidated Phox $2 b$ allele $\left(P h o x 2 b^{+/-}\right.$ mice) show sleep apneas (Durand et al., 2005) and reduced sensitivity to hypercapnia (Dauger et al., 2003; Ramanantsoa et al., 2007). Taken together, these studies demonstrate the important role of Phox $2 b$ in the postnatal control of breathing.

In newborns, ventilatory control is tightly coupled with thermoregulation. This coupling allows the fine-tuning of $\mathrm{O}_{2}$ demand and supply, and enables the organism to cope with metabolic challenges (Mortola, 1999; Steiner and Branco, 2002; Chardon et al., 2004; Gargaglioni et al., 2005). In particular, newborns respond to oxygen demand by increasing ventilation, and then, if the demand persists, by decreasing the metabolic rate, thermogenesis and ventilation, an effect designated "hypoxic hypometabolism" (Frappell et al., 1992, 1998; Mortola, 1999, 2005; Bollen et al., 2009). The decrease in thermogenesis reflects a centrally regulated response rather than the mere limitation of oxygen availability (Mortola and Gautier, 1995; Gautier, 1996; Osaka, 2010). Hypoxic hypometabolism is regarded as an important response for the protection of vital organs, especially the brain, from hypoxic stress during the neonatal period. The mechanisms underlying the coupling between ventilatory control and thermoregulation are still elusive 
(see Osaka, 2010 for a recent review). Our present hypothesis is that Phox $2 b$, which regulates the development of neuronal circuits underlying both functions, may be important to their combined control in newborns.

The aim of the present study was to assess the role of Phox $2 b$ in thermoregulation and ventilatory control in newborns. To this end, we measured ventilatory and thermoregulatory responses to hypoxic stress in Phox $2 b^{+/-}$newborn mouse pups. We exposed 6-day-old Phox $2 b^{+/-}$pups and their wild-type littermates (Phox $2 b^{+/+}$) to chemical stimuli (hypoxia or hypercapnia) under cold or thermoneutral conditions. All variables were measured non-invasively in unrestrained pups to avoid any confounding effect of behavioral stress. Finally, since serotonergic neurons depend on Phox $2 b$ for their differentiation (Jacob et al., 2007) and are closely involved in respiratory function and in the thermogenic response to cold (Hilaire et al., 2010; Hodges and Richerson, 2010; Madden and Morrison, 2010), we explored the role of serotonin (5-HT) in the above process by measuring brain levels of the neurotransmitter.

\section{MATERIALS AND METHODS ANIMALS}

The generation and genotyping of Phox $2 b^{+/-}$mice have been described elsewhere (Pattyn et al., 1999). Since respiratory control disorders are frequent in preterm infants and represent a major risk of brain hypoxia, we conducted this study in 6-day-old pups. This postnatal age roughly corresponds to 35 weeks of gestation in humans in terms of central nervous system development (Hagberg et al., 2002). Mice were housed at $21^{\circ} \mathrm{C}$ with a 12 -h light/dark cycle (lights on at 7 a.m.) and fed ad libitum. The animals were randomly assigned to four experimental groups: hypoxia at $26^{\circ} \mathrm{C}$, hypoxia at $33^{\circ} \mathrm{C}$, hypercapnia at $26^{\circ} \mathrm{C}$ and hypercapnia at $33^{\circ} \mathrm{C}$. Each litter was assigned to one experimental group. All quantifications were performed blind regarding the genotypes, which were determined after all tests were completed. Previous experiments in newborn mice (Bollen et al., 2009) indicated that the physiological responses to cold showed a large interindividual variability, which required a larger sample size in this condition.

Experimental protocols were approved by the Institutional Review Committee. All animal tests were performed in accordance with the European Communities Council Directive (86/809/EEC) regarding the care and use of animals for experimental procedures, in compliance with the regulations of the Ministère de l'Agriculture et de la Forêt, Service Vétérinaire de la Santéet de la Protection Animale (permission \# A 94-028-21). All efforts were made to minimize animal suffering, especially by using fully non-invasive functional tests.

\section{PLETHYSMOGRAPHY}

Breathing variables were measured non-invasively using a battery of four whole-body flow barometric plethysmography, allowing the simultaneous measurement of breathing variables as previously described (Bollen et al., 2009). We used whole-body flow barometric plethysmography, rather than head-out plethysmography which provides a relatively direct measure of breathing, to avoid the stress related to restraint. Whole-body flow barometric plethysmography provides semiquantitative measurements of tidal volume and ventilation, and valid measurements of breathing frequency and apnea. Despite these limitations, this latter technique remains the only non-invasive method for studying unrestrained newborn mice.

Each plethysmograph was composed of two $50 \mathrm{ml}$ Plexiglas chambers, immersed in a water-bath to maintain their temperature at 26 or $33^{\circ} \mathrm{C}$. A $200 \mathrm{ml} \mathrm{min}^{-1}$ flow of dry air (Brooks airflow stabilizer, Urlo, Holland) was divided into two $100 \mathrm{ml} \mathrm{min}^{-1}$ flows through the chambers. The differential pressure between the chambers (DRUCK-EFFA transducer, Asnières, France) was filtered (bandwidth: $0.15-20 \mathrm{~Hz}$ at $-3 \mathrm{~dB}$ ), converted into a digital signal at a sampling rate of $100 \mathrm{~Hz}$, and processed (Labview, National Instruments, Austin, TX, USA). Calibration was done before each session using a built-in pump incorporating a microsyringe (Ito corporation, Fuji, Japan), which injected a sinusoidal airflow with a maximum amplitude of $2 \mu \mathrm{l}$ and a frequency of $8 \mathrm{~Hz}$ into the animal chamber. The limitations of the plethysmographic method in newborn mice (Enhorning et al., 1998; Mortola and Frappell, 1998) have been discussed elsewhere (Lofaso et al., 2007). Because of these limitations, the absolute values given for the tidal volume $\left(V_{\mathrm{T}}\right)$ and ventilation $\left(V_{\mathrm{E}}\right)$ are indicative only, whereas the absolute values for breath duration $\left(T_{\mathrm{TOT}}\right)$ and the duration of apnea, as well as the relative changes from baseline of $V_{\mathrm{T}}, T_{\mathrm{TOT}}$, and $V_{\mathrm{E}}$, are reliable.

\section{BREATHING VARIABLES}

$T_{\text {TOT }}(\mathrm{s}), V_{\mathrm{T}}\left(\mu \mathrm{lg}^{-1}\right.$ BTPS), and $V_{\mathrm{E}}$ (calculated as $V_{\mathrm{T}} T_{\mathrm{TOT}}{ }^{-1}$ and expressed in $\mu \mathrm{ls}^{-1} \mathrm{~g}^{-1}$ BTPS) were calculated from apneafree periods (see apnea determination below). Breath-by-breath values for $V_{\mathrm{E}}, V_{\mathrm{T}}$, and $T_{\mathrm{TOT}}$ were averaged over consecutive $30 \mathrm{~s}$ periods. The baseline levels of these variables were calculated as the mean level during the 3-min of air breathing that preceded exposure to hypoxia or hypercapnia. The time course of $V_{\mathrm{E}}$ in response to hypoxia or hypercapnia was expressed as the percentage of change of $V_{\mathrm{E}}\left(\Delta V_{\mathrm{E}}\right)$ over consecutive $30 \mathrm{~s}$ periods during the 3-min of hypoxia or $6 \mathrm{~min}$ of hypercapnia, relative to the last $30 \mathrm{~s}$ of air breathing that preceded gaseous exposure. The ventilatory response to hypoxia was also expressed as the percentage change in $V_{\mathrm{E}}$ relative to the average baseline $V_{\mathrm{E}}$, using the formula $100 \cdot\left(\right.$ peak- $V_{\mathrm{E}}$ - baseline $V_{\mathrm{E}}$ )/baseline $V_{\mathrm{E}}$. The peak- $V_{\mathrm{E}}$ response to hypoxia was determined individually as the highest of the 6 mean- $V_{\mathrm{E}}$ values (calculated over $30 \mathrm{~s}$ ) during the 3min hypoxic exposure. This method took into account possible interindividual differences in the delay to the peak- $V_{\mathrm{E}}$ response to hypoxia. We determined the $V_{\mathrm{T}}$ and $T_{\text {TOT }}$ responses to hypoxia using the same formula, using $V_{\mathrm{T}}$ and $T_{\text {TOT values measured at }}$ peak- $V_{\mathrm{E}}$. The peak- $V_{\mathrm{E}}$ response to hypercapnia was calculated along the same lines. Similarly, HVD was assessed as the maximal decrease of $V_{\mathrm{E}}$ in response to hypoxia. We previously reported that $V_{\mathrm{E}}$ started to decrease during hypoxia, about $90 \mathrm{~s}$ after the switch to hypoxia, but it invariably reached its minimum value over the 3-min period following the switch back to air (Bollen et al., 2009). Although we termed this response HVD, we cannot discard that it involved after effects of hypoxia, i.e., post-hypoxic ventilatory decline (PHVD). HVD and PHVD basically reflect the same neuronal inhibitory mechanisms, the difference being that PHVD is maximally expressed when the excitatory component 
of the response to hypoxia is no longer present (Coles and Dick, 1996).

Apneas were defined as ventilatory pauses longer than twice the duration of the preceding breath (Sawnani et al., 2004). Total apnea duration was calculated over successive $30 \mathrm{~s}$ periods. The apnea response to hypoxia was expressed as the absolute difference between total apnea duration during hypoxia and the same measurement for the 30-s period preceding hypoxia. Percentages were not calculated as some mice had no apneas during normoxia, especially at $26^{\circ} \mathrm{C}$.

\section{HEART RATE}

In a separate experiment, we measured the heart rate (HR) in unrestrained pups. The plethysmographic chambers were equipped with recording platforms composed of four rectangular gold electrodes insulated from one another and embedded in the floor of the chamber, as previously described (Ramanantsoa et al., 2007). Conduction was enhanced using electrode hydrogel (Sekisui Plastics Co., Ltd., Nara, Japan). Signals were digitized at a sampling rate of $1000 \mathrm{~Hz}$ (16 bits, PCI-6229, National Instruments, Austin, TX, USA). An ECG signal was obtained when at least three paws were in contact with three different electrodes or, occasionally, when the pup was lying down on the floor. HR was determined from R-R wave peaks after visual selection of continuous ECG segments of $1 \mathrm{~s}$ or more with clearly defined QRS waves.

\section{ULTRASONIC VOCALIZATIONS}

Ultrasonic vocalizations (USVs) were recorded using an ultrasound bat detector, D230 (Petterson Elektronik AB, Uppsala, Sweden), as previously described (Bollen et al., 2009).

\section{VENTILATORY TESTS}

After 15 min of normoxia, hypoxia was achieved by switching the airflow through the plethysmograph to $10 \% \mathrm{O}_{2}+90 \% \mathrm{~N}_{2}$ at the same flow rate $\left(100 \mathrm{ml} \mathrm{min}^{-1}\right.$ per chamber) for $3 \mathrm{~min}$, after which the flow was switched back to normoxia for $12 \mathrm{~min}$ (total duration of the session: $30 \mathrm{~min}$ ). Hypercapnia was achieved by switching the airflow through the plethysmograph to $8 \% \mathrm{CO}_{2}+21 \% \mathrm{O}_{2}+71 \%$ $\mathrm{N}_{2}$ for $6 \mathrm{~min}$, after which the flow was switched back to normoxia for $9 \mathrm{~min}$ (total duration of the session: $30 \mathrm{~min}$ ). We used a longer $\mathrm{CO}_{2}$ stimulus, compared to hypoxia, because the $V_{\mathrm{E}}$ response to $8 \% \mathrm{CO}_{2}$ reaches its peak-value only after $2-3 \mathrm{~min}$ of stimulation in newborn mice (Ramanantsoa et al., 2007).

\section{THERMAL CHALLENGE}

Experiments were conducted at 33 or at $26^{\circ} \mathrm{C}$ by controlling the temperature of the water surrounding the plethysmographic chambers. Previous analysis in newborn mice has indicated that a temperature of $26^{\circ} \mathrm{C}$ elicits near-maximal thermogenesis by brown adipose tissue, and may therefore be considered as extreme cold (Bollen et al., 2009). In contrast, $33^{\circ} \mathrm{C}$ approaches thermoneutrality and corresponds to the temperature within litters of newborn mice in contact with their mother (Renolleau et al., 2001).

\section{BODY TEMPERATURE}

We directly measured interscapular skin temperature in all pups in the study, before and immediately after plethysmographic recording, by placing a thermocouple probe at the level of the interscapular region. In a separate experiment, we also measured the emission of infrared (IR) radiation from the skin surface of the interscapular region in the cold, as previously described (Bollen et al., 2009). This was done using an infrared camera (FLIR Systems Thermovision A20, Boston, MA, USA) which was mounted over one of the plethysmograph animal chambers. IR measurement was done through a special window of the plethysmograph chamber made of Zinc Selenide, to ensure permeability to IR emission.

\section{$\mathrm{O}_{2}$ CONSUMPTION}

In a separate experiment, we measured the time course of $\mathrm{O}_{2}$ consumption (corrected for body weight, $\mu \mathrm{l} \mathrm{min}^{-1} \mathrm{~g}^{-1}$ ) in pups exposed to hypoxia (hypercapnia elicits no metabolic response in newborns; Saiki and Mortola, 1996; Putnam et al., 2005) in cold and thermoneutral conditions. To do this, we used a method described previously (Bollen et al., 2009). A fan was placed in the chamber to stir the ambient gas and ensure constant washout kinetics regardless of the position of the pup. This method allowed the calculation of the time course of $\mathrm{O}_{2}$ consumption in conditions of variable $\mathrm{FiO}_{2}$. However the fan disrupted the ventilatory signal, precluding the calculation of the $\mathrm{V}_{\mathrm{E}} / \mathrm{VO}_{2}$ ratio. We calculated a rough estimation of this ratio within each genotype on subgroups of the hypoxic experiment weight-matched to the $\mathrm{VO}_{2}$ experiment groups. To do this, we divided individual $V_{\mathrm{E}}$ values by the value of $\mathrm{VO}_{2}$ of the corresponding genotype group over the same periods (3-min preceding hypoxia, time of the peak- $V_{\mathrm{E}}$ response to hypoxia, and time of the minimum $V_{\mathrm{E}}$ response to hypoxia).

\section{ANALYSIS OF SEROTONERGIC METABOLISM}

Brains were dissected and kept at $-80^{\circ} \mathrm{C}$ until analysis as previously reported (Ramirez and Viemari, 2005). Brain levels of serotonin (5-HT), its precursor L-tryptophan (L-Trp) and its main 5-HT metabolite from the monoamine oxidase A (MAOA) degradation pathway, 5-hydroxyindoleacetic acid (5-HIAA), were measured using high pressure liquid chromatography (HPLC) and electrochemical detection (Waters System: pump P510, electrochemical detector EC2465; Atlantis column DC18; mobile phase: citric acid, $50 \mathrm{mM}$; orthophosphoric acid, $60 \mathrm{mM}$; sodium octanesulfonic acid, $0.112 \mathrm{mM}$; EDTA: $0.06 \mathrm{mM}$, methanol; $\mathrm{pH}$ 3.01).

\section{STATISTICS}

All respiratory variables were averaged over consecutive $30 \mathrm{~s}$ periods and subjected to analysis of variance with genotype $\left(\right.$ Phox $2 b^{+/-}$versus wild-type Phox $2 b^{+/+}$) and temperature (26 versus $33^{\circ} \mathrm{C}$ ) as the between-subjects factors. Litter had no significant effect, neither as a main between-factor nor in interaction with other factors analyzed, and will not be mentioned further. We also conducted complementary analyses using weight-matched groups to determine whether any differences between $P h o x 2 b^{+/+}$ and Phox $2 b^{+/-}$pups were related to weight. Since all analyses yielded the same statistical results as those obtained using the entire population, this variable will not be mentioned further. In all tests, a $p$-value of $\leq 0.05$ was considered to indicate a significant difference. Group means compared by ANOVA are presented 
along with SD in the text and the tables. SEM are used in the figures for the sake of clarity. All statistical analyses were conducted using StatView 5 (Abacus Concepts, Berkeley, CA, USA).

\section{RESULTS}

\section{GREATER TEMPERATURE DROP IN THE COLD IN Phox $\mathbf{b}^{+/-}$PUPS}

Phox $2 b^{+l-}$ pups weighed significantly less than their wild-type littermates (Table 1). Before plethysmography, body temperatures measured (with a thermocouple) immediately after taking the pup from the litter were highly similar in Phox $2 \mathrm{~b}^{+/-}$and Phox $2 b^{+/+}$ pups (Table 1). In contrast, when exposed to $26^{\circ} \mathrm{C}$, body temperatures (measure by infrared thermography) were lower in Phox $2 b^{+/-}$pups than in their Phox $2 b^{+/+}$littermates, in both hypoxic and hypercapnic studies (Figure 1). Thus, Phox $2 b^{+/-}$ pups showed a reduced ability to maintain body temperature in the cold.

\section{DEPRESSED BASELINE VENTILATION IN THE COLD IN Phox $\mathbf{b}^{+/-}$PUPS}

At $33^{\circ} \mathrm{C}$, baseline normoxic $V_{\mathrm{E}}$ values were highly similar in Phox $2 b^{+/+}$and Phox $2 b^{+/-}$pups (Table 2 ). The cold stimulated $V_{\mathrm{E}}$ in both genotype groups, although this effect was significantly lower in Phox $2 b^{+/-}$pups (Table 2). This difference was further supported by apnea analysis. Apnea duration was longer in Phox $2 b^{+l-}$ than in Phox $2 b^{+/+}$pups both at 33 and at $26^{\circ} \mathrm{C}$ (Table 2). Whereas the effect of the cold on apnea duration in Phox $2 b^{+1+}$ pups was minimal, it significantly increased apnea duration in Phox $2 b^{+/-}$pups (Table 2). Thus, the ventilatory response to cold was markedly disrupted in Phox $2 b^{+1-}$ pups. The HR was diminished by the cold in both groups, without significant genotype-related differences. Behaviorally, the cold similarly stimulated movement and USV generation in Phox $2 b^{+/-}$and
Phox $2 b^{+/+}$pups (Table 2), suggesting that the perception of cold was not altered in Phox $2 b^{+/-}$pups.

\section{ABNORMAL VENTILATORY RESPONSE TO HYPOXIA IN THE COLD IN Phox $2 b^{+/-}$PUPS}

At $33^{\circ} \mathrm{C}$, the ventilatory response to hypoxia displayed similar trends in the Phox $2 b^{+l+}$ and Phox $2 b^{+l-}$ groups (Figure 2A), despite small but significant differences in the peak hyperpneic $V_{\mathrm{E}}$ response and in the HVD (Table 3 ). In both genotype groups, the cold depressed the $V_{\mathrm{E}}$ response to hypoxia compared to $33^{\circ} \mathrm{C}$ conditions, leading to reduced hyperpneic responses and an increased HVD (Figure 2B; Table 3). However, these effects of the cold were less marked in Phox $2 b^{+/-}$than in Phox $2 b^{+/+}$pups (Figures 2A,B; Table 3). As a result, in the cold, $P$ hox $2 b^{+/-}$pups showed a larger hyperpneic response to hypoxia than $P h o x 2 b^{+/+}$pups, due mostly to the greater drop in $T_{\mathrm{TOT}}$ (Figure $2 \mathrm{~B}$; Table 3 ). In line with their stronger hyperpneic response, the HVD in Phox $2 b^{+/-}$pups was depressed when compared to Phox $2 b^{+/+}$pups (Figure 2B; Table 3). Estimated $\mathrm{V}_{\mathrm{E}} / \mathrm{VO}_{2}$ ratios at the time of the peak- $V_{\mathrm{E}}$ response to hypoxia were larger in $P h o \times 2 b^{+/-}$pups, compared to Phox $2 b^{+1+}$ pups at both temperatures $\left(33^{\circ} \mathrm{C}: 214 \pm 22\right.$ versus $85 \pm 11, p<0.0001 ; 26^{\circ} \mathrm{C}: 52 \pm 24$ versus $\left.38 \pm 10, p<0.0001\right)$. In contrast, estimated $\mathrm{V}_{\mathrm{E}} / \mathrm{VO}_{2}$ ratios were smaller in Phox $2 b^{+/-}$ pups, compared to Phox $2 b^{+/+}$during $\operatorname{HVD}\left(33^{\circ} \mathrm{C}\right.$ : $15 \pm 1$ versus $17 \pm 1, p<0.0006 ; 26^{\circ} \mathrm{C}: 22 \pm 9$ versus $\left.32 \pm 10, p<0.0001\right)$.

Apneas were nearly absent and showed no significant changes in response to hypoxia in Phox $2 b^{+/+}$pups at either temperature. In contrast, apneas occurred in Phox $2 b^{+/-}$pups, and showed longer total durations than in Phox $2 b^{+/+}$pups, especially in the cold; apneas markedly decreased in response to hypoxia, and then markedly increased during the HVD (Figure 2B). However, total

Table 1 |Weight and temperature of 6-day-old Phox2 $\boldsymbol{b}^{+/-}$and Phox2 $\mathrm{b}^{+/+}$mice.

\begin{tabular}{|c|c|c|c|c|c|c|c|}
\hline & \multicolumn{3}{|c|}{$33^{\circ} \mathrm{C}$} & \multicolumn{3}{|c|}{$26^{\circ} \mathrm{C}$} & \multirow{2}{*}{$\begin{array}{l}\mathbf{G} \times T \\
p\end{array}$} \\
\hline & Phox2b ${ }^{+/+}$ & Phox2b ${ }^{+/-}$ & $p$ & Phox2b ${ }^{+/+}$ & Phox2b ${ }^{+/-}$ & $p$ & \\
\hline \multicolumn{8}{|c|}{ HYPOXIA STUDY } \\
\hline$n$ & 41 & 43 & & 84 & 85 & & \\
\hline Weight (g) & $3.4(0.5)$ & $2.8(0.4)$ & $<0.0001$ & $3.7(0.6)^{*}$ & $3.0(0.5)^{*}$ & $<0.0001$ & NS \\
\hline$T^{\circ}$ initial $\left({ }^{\circ} \mathrm{C}\right)$ & $33.9(1.1)$ & $33.7(1.0)$ & NS & $33.5(1.5)$ & $33.3(1.4)$ & NS & NS \\
\hline$T^{\circ}$ final $\left({ }^{\circ} \mathrm{C}\right)$ & $34.8(0.6)$ & $34.6(0.7)$ & NS & $30.5(1.1)^{* * * *}$ & $29.8(1.4)^{* * * *}$ & $<0.0003$ & $<0.0608$ \\
\hline$T^{\circ}$ chamber $\left({ }^{\circ} \mathrm{C}\right)$ & $33.0(0.3)$ & $33.0(0.3)$ & NS & $26.0(0.3)$ & $26.0(0.2)$ & NS & NS \\
\hline$T^{\circ}$ infrared $\left({ }^{\circ} \mathrm{C}\right)$ & - & - & & $31.8(0.6)$ & $30.8(1.1)$ & 0.0001 & - \\
\hline \multicolumn{8}{|c|}{ HYPERCAPNIA STUDY } \\
\hline$n$ & 34 & 36 & & 51 & 45 & & \\
\hline Weight (g) & $3.7(0.5)$ & $3.4(0.7)$ & $<0.0439$ & $3.7(0.5)$ & $3.3(0.7)$ & 0.0006 & NS \\
\hline$T^{\circ}$ initial $\left({ }^{\circ} \mathrm{C}\right)$ & $34.3(1.1)$ & $34.4(1.2)$ & NS & $34.1(1.4)$ & $33.7(1.4)^{*}$ & NS & NS \\
\hline$T^{\circ}$ final $\left({ }^{\circ} \mathrm{C}\right)$ & $34.8(1.2)$ & $34.9(0.8)$ & NS & $30.8(1.0)^{* * * *}$ & $30.4(0.8)^{* * * *}$ & 0.0321 & NS \\
\hline$T^{\circ}$ chamber $\left({ }^{\circ} \mathrm{C}\right)$ & $33.0(0.4)$ & $32.9(0.4)$ & NS & $26.2(0.4)$ & $26.2(0.4)$ & NS & \\
\hline
\end{tabular}

Weight and interscapular skin temperature were measured immediately after taking the pup from the litter ( $T^{\circ}$ initial). The $p$-value refers to the comparison between Phox $2 b^{+/+}$and Phox $2 b^{+/-}$groups. Comparison of 33 versus $26^{\circ} \mathrm{C}$ for each genotype group; * $p<0.05$; **** $p<0.0001$. Values indicate mean (SD) for each group. G $\times$ T: p-value for Genotype by Temperature interaction. Note that $G \times T$ interactions were marginally significant in the hypoxic study and therefore that genotype-related differences in final temperatures are unwarranted. Infrared temperature were not measured at $33^{\circ} \mathrm{C}$, due to the lack of infrared image of the pup in thermoneutral conditions. 


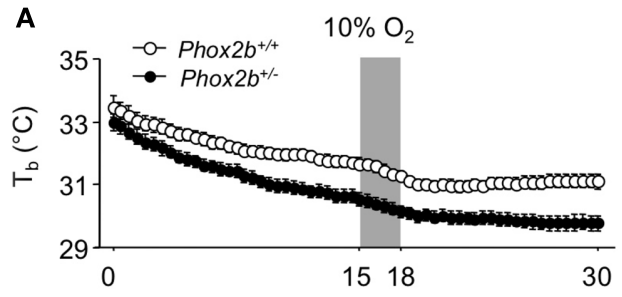

C

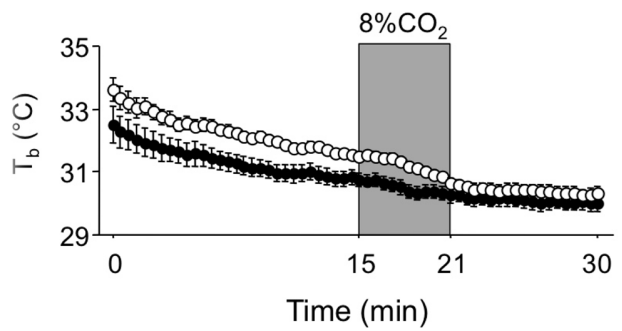

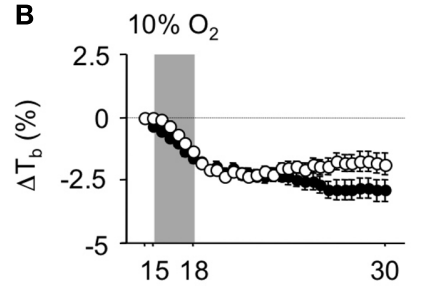

D

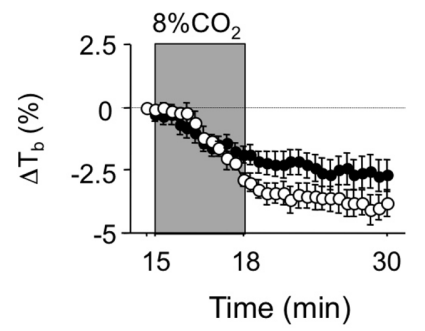

FIGURE 1 | Body temperature $\left(T_{\mathrm{b}}\right)$ in Phox $2 \mathrm{~b}^{+/+}$and $\boldsymbol{P h o x} 2 \mathrm{~b}^{+/-}$pups

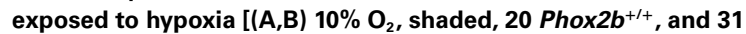

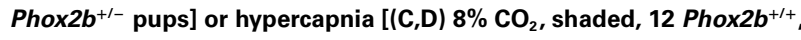
and 20 Phox $2 b^{+/-}$pups] at an ambient temperature of $26^{\circ} \mathrm{C}$. Body temperature was measured at the level of interscapular brown adipose tissue by infrared thermography. Values are absolute levels $(\mathbf{A}, \mathbf{C})$ and relative changes from pre-stimulus levels (B,D). Body temperature progressively decreased, revealing an inability to maintain core temperature, especially in Phox $2 b^{+/-}$pups $(\mathbf{A}, \mathbf{C})$. Both hypoxic and hypercapnic stimuli induced a reduction in body temperature $(\mathbf{A}, \mathbf{C})$. Hypoxia induced similar temperature losses in Phox $2 b^{+/+}$and Phox $2 b^{+/-}$pups, but temperature recovery long after the return to normoxia was blunted only in Phox $2 b^{+-}$pups (B). In contrast, the temperature loss after hypercapnia was blunted in Phox $2 b^{+/-}$pups (D). Values indicate means \pm SEM for the group.

Table 2 | Baseline cardiorespiratory variables.

\begin{tabular}{|c|c|c|c|c|c|c|c|}
\hline & \multicolumn{3}{|c|}{$33^{\circ} \mathrm{C}$} & \multicolumn{3}{|c|}{$26^{\circ} \mathrm{C}$} & \multirow{2}{*}{$\begin{array}{l}\mathbf{G} \times T \\
p\end{array}$} \\
\hline & Phox2b ${ }^{+/+}$ & Phox2b $b^{+/-}$ & $p$ & Phox2b $b^{+/+}$ & Phox2b $b^{+/-}$ & $p$ & \\
\hline$n$ & 75 & 79 & & 135 & 130 & & \\
\hline$V_{E}\left(\mu \mid s^{-1} g^{-1}\right)$ & $16.3(2.3)$ & $16.3(2.5)$ & NS & $29.8(10.8)^{* * * *}$ & $21.5(11.7)^{* * * *}$ & $<0.0001$ & $<0.0001$ \\
\hline$V_{T}\left(\mu \mid g^{-1}\right)$ & $5.4(0.6)$ & $5.6(0.8)$ & NS & $8.6(1.70)^{* * * *}$ & $7.9(2.8)^{* * * *}$ & 0.0098 & $<0.0148$ \\
\hline$T_{\text {TOT }}(\mathrm{s})$ & $0.34(0.1)$ & $0.35(0.1)$ & NS & $0.3(0.1)$ & $0.4(0.1)^{* * * *}$ & $<0.0001$ & $<0.0001$ \\
\hline Apneas (s) & $0.3(0.3)$ & $0.7(1.1)$ & 0.0024 & $0.2(1.2)$ & $2.3(4.4)^{* * *}$ & $<0.0001$ & $<0.0011$ \\
\hline MVT (s) & $2.0(2.8)$ & $1.91(2.9)$ & NS & $2.6(3.5)$ & $3.4(4.3)^{* *}$ & NS & NS \\
\hline USV (s) & $0.02(0.07)$ & $0.02(0.04)$ & NS & $0.51(0.57)^{* * * *}$ & $0.48(0.65)^{* * * *}$ & NS & NS \\
\hline $\mathrm{VO}_{2}(\mathrm{ml} / \mathrm{min} / \mathrm{g}) n$ & 43.9 (13.3) 8 & $38.6(7.1) 5$ & NS & $71.8(5.8) * * * * 10$ & $52.4(19.2) 17$ & $<0.0049$ & $\mathrm{NS}^{\dagger}$ \\
\hline $\mathrm{HR}(\mathrm{bpm}) n$ & $511(68) 27$ & 492 (64) 22 & NS & $461(60)^{* * *} 57$ & $453(70)^{*} 61$ & NS & NS \\
\hline
\end{tabular}

Values indicate mean (SD) for each group, calculated over the 3-min preceding the hypoxic or hypercapnic stimulus. Apnea, MVT, USV=total apnea, movement duration, and ultrasonic vocalization(s) over 30 s periods, respectively. HR: heart rate (beats $\min ^{-1}$ ). Comparison of 33 versus $26{ }^{\circ} \mathrm{C}$ for each genotype group; ${ }^{*} p<0.05$; ${ }^{*} p<0.01 ;{ }^{* *} p<0.001 ; * * * *<0.0001 ; p$-value refers to the comparison between Phox $2 b^{+/+}$and Phox $2 b^{+/-}$groups. G $\times$T: $p$-value for Genotype by Temperature interaction. ${ }^{\dagger}$ :complete analysis of $\mathrm{VO}_{2}$ over the entire air period yielded significant interaction (see text). Oxygen consumption (VO ${ }_{2}$ ) and heart rate (HR) studies were conducted on separate groups of mice. The estimated $V_{E} N_{2}$ ratios on weighted matched subgroups indicated a significant difference between Phox $2 b^{+/+}$and Phox $2 b^{+-}$groups at $33^{\circ} \mathrm{C}[20.78(1.92), n=11$, versus $38.77(3.88), n=22, p<0.0001]$, but not at $26^{\circ} \mathrm{C}[29.31$ (8.29), $n=44$ versus $27.37(10.21), n=56, N S]$.

apnea duration remained low in $P h o \times 2 b^{+/-}$pups ( $<3$ s out of $30 \mathrm{~s}$; Figure 2B).

\section{DISRUPTED V0 2 RESPONSE TO COLD IN Phox $2 b^{+/-}$PUPS}

Firstly, due to their complex pattern, $\mathrm{VO}_{2}$ data were analyzed over the entire normoxic periods in cold and thermoneutral conditions (Figure 3). The comparison of the time courses of $\mathrm{VO}_{2}$ between Phox $2 \mathrm{~b}^{+/-}$and Phox $2 \mathrm{~b}^{+/+}$pups yielded different results at 33 and $26^{\circ} \mathrm{C}$ (Genotype by Temperature by Time interaction, $p<0.0001$ ). At $33^{\circ} \mathrm{C}$, the time courses of $\mathrm{VO}_{2}$ were similar in Phox $2 \mathrm{~b}^{+/-}$and Phox $2 \mathrm{~b}^{+/+}$pups (Genotype by Time interaction: NS; Figure 3A). In contrast, at $26^{\circ} \mathrm{C}$, these time courses were markedly different in Phox $2 \mathrm{~b}^{+/-}$and Phox $2 \mathrm{~b}^{+/+}$pups, due to smaller $\mathrm{VO}_{2}$ increase and steady state in Phox $2 b^{+/-}$pups (Genotype by Time interaction, $p<0.0001$; Figure 3C; Table 2). Thus, the $\mathrm{VO}_{2}$ response to cold was markedly altered in $P h o x 2 b^{+/-}$pups. The reduced $\mathrm{VO}_{2}$ 

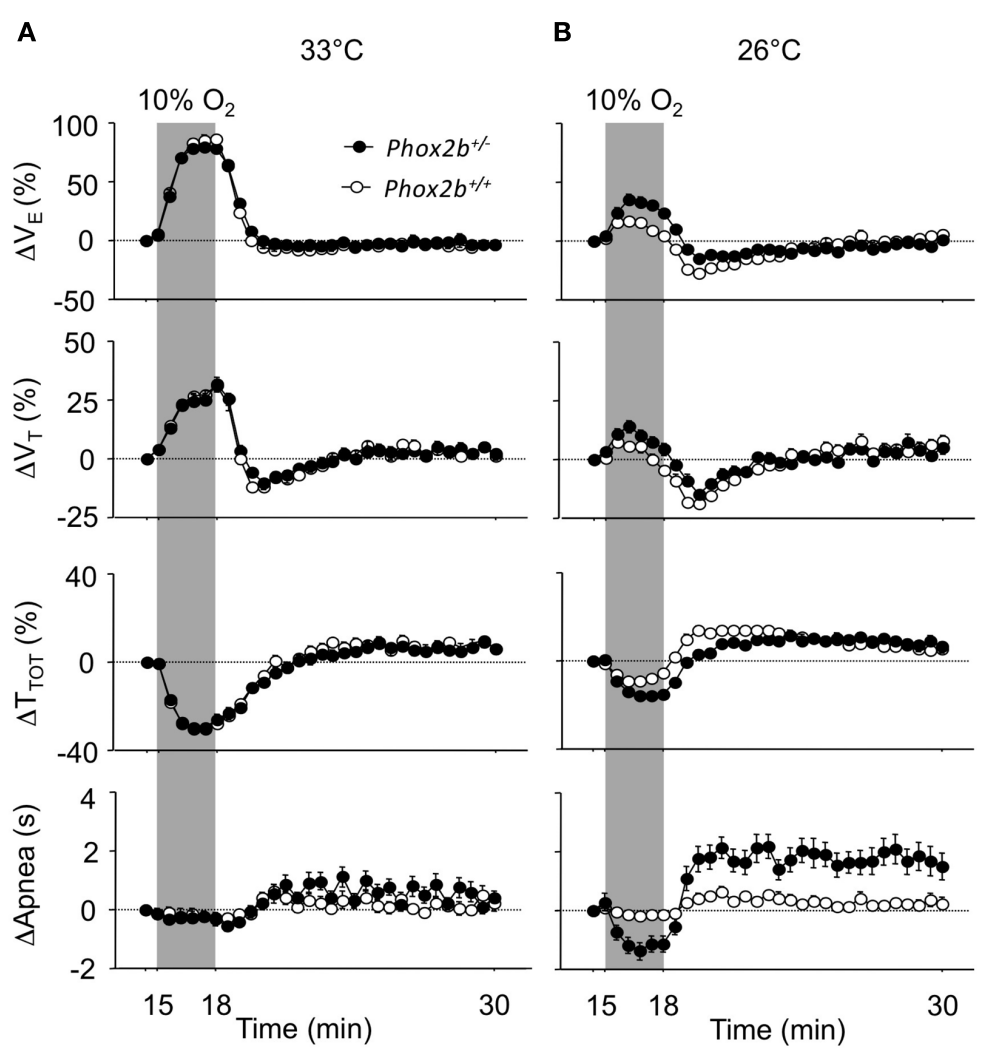

FIGURE 2 | Ventilatory responses to hypoxia $\left(10 \% \mathrm{O}_{2}\right.$, shaded) in Phox $2 b^{+/+}$and $P h o x 2 b^{+/-}$pups at $33^{\circ} \mathrm{C}(\mathrm{A})$ and $26^{\circ} \mathrm{C}$ (B). $V_{\mathrm{E}}$ : ventilation; $T_{\text {TOT }}$ : breath duration; $V_{\mathrm{T}}$ : tidal volume. Apnea: total apnea duration $/ 30 \mathrm{~s}$. Values are expressed as percentage changes from pre-hypoxic levels for $V_{E}, V_{T}$, and $T_{\text {Tот. }}$. Apnea durations are expressed as absolute changes from pre-hypoxic levels. Latency to peak- $V_{E}$ from the onset of hypoxia shows wide interindividual variability (see Table 3), which smoothens the difference between the mean- $V_{E}$ curves. At $33^{\circ} \mathrm{C}$, breathing variables are similar in Phox $2 b^{+/+}$and Phox $2 b^{+/-}$pups, although Phox $2 b^{+/-}$pups have a slightly smaller $V_{E}$ response to hypoxia (see Table 3 for statistical analyses). The HVD is more sustained in Phox $2 b^{+/-}$pups than in Phox $2 b^{+/+}$pups exposed to cold. Values indicate means \pm SEM for each group. See Table 1 for group sizes. response to cold in Phox $2 b^{+/-}$pups is in line with their lower body temperatures and $V_{\mathrm{E}}$ (Table 2).

\section{DISRUPTED HYPOXIC HYPOMETABOLISM IN Phox2b $b^{+/-}$PUPS}

The analysis of $\mathrm{VO}_{2}$ response to hypoxia (especially when expressed as percent changes from pre-hypoxic levels) yielded different results in Phox $2 b^{+/-}$and Phox $2 b^{+/+}$pups (Genotype by Temperature by Time interaction, $p<0.0001$; Figures 3B,D). At $33^{\circ} \mathrm{C}$, the magnitude of the drop in $\mathrm{VO}_{2}$ (relative to pre-hypoxic levels) was greater in Phox $2 b^{+/-}$pups than in wild-type controls although this difference was not significant (Genotype by Time interaction: NS; Figure 3B). In contrast, at $26^{\circ} \mathrm{C}$, the entire pattern of $\mathrm{VO}_{2}$ changes was altered in Phox $2 b^{+/-}$pups, so that the time course of $\mathrm{VO}_{2}$, relative to pre-hypoxic levels, was practically in phase opposition between Phox $2 b^{+/-}$and Phox $2 b^{+/+}$pups (Genotype by Time interaction: $p<0.0001$; Figure 3D). These results indicate that the metabolic response to the cold and hypoxia was profoundly affected by the Phox 2 b mutation.

\section{ABNORMAL VENTILATORY RESPONSE TO HYPERCAPNIA IN THE COLD IN Phox2b+l- PUPS}

At $33^{\circ} \mathrm{C}$, the $V_{\mathrm{E}}$ response to hypercapnia was significantly reduced in Phox $2 b^{+/-}$than in Phox $2 b^{+/+}$pups, as previously reported
(Dauger et al., 2003; Durand et al., 2005; Ramanantsoa et al., 2007). This difference in $V_{\mathrm{E}}$ was due to lower responses in both $T_{\text {TOT }}$ and $V_{\mathrm{T}}$, but mostly $V_{\mathrm{T}}$, in Phox $2 b^{+/-}$pups (Figures $4 \mathrm{~A}, \mathbf{B}$; Table 3).

The cold depressed the ventilatory response to hypercapnia in Phox $2 b^{+1+}$ but not in Phox $2 b^{+/-}$pups (Figures 4A,B; Table 3 ). This difference was mainly due to the fact that, in the cold, $V_{\mathrm{E}}$ was reduced in Phox $2 b^{+/+}$pups before the end of exposure to hypercapnia (hypercapnic ventilatory decline). In contrast, in Phox $2 b^{+/-}$pups, the $V_{\mathrm{E}}$ response to hypercapnia was sustained throughout the hypercapnic stimulus (Figures 4A,B; Table 3). The difference in the $V_{\mathrm{E}}$ response to hypercapnia between the two genotype groups was mainly due to differences in $T_{\text {TOT }}$. The absence of a hypercapnic ventilatory decline in $P h o \times 2 b^{+/-}$pups led to a larger $V_{\mathrm{E}}$ response during the last $3 \mathrm{~min}$ of hypercapnic exposure in Phox $2 b^{+l-}$ than in Phox $2 b^{+/+}$pups (Figures 4A,B; Table 3).

These differences in the $V_{\mathrm{E}}$ response to $\mathrm{CO}_{2}$ were apparently not related to arousal. In fact, at $33^{\circ} \mathrm{C}$, movement duration (MVT) and USV duration in response to hypercapnia were practically absent in both genotype groups. In the cold, the USV and MVT responses to hypercapnia were similar in both genotype groups (data not shown). 
Table 3 | Ventilatory responses to hypoxia and hypercapnia.

\begin{tabular}{|c|c|c|c|c|c|c|c|}
\hline & \multicolumn{3}{|c|}{$33^{\circ} \mathrm{C}$} & \multicolumn{3}{|c|}{$26^{\circ} \mathrm{C}$} & \multirow{2}{*}{$\begin{array}{l}\mathrm{G} \times T \\
p\end{array}$} \\
\hline & Phox2b $b^{+/+}$ & Phox2b $b^{+/-}$ & $p$ & Phox2b $b^{+/+}$ & Phox2b $b^{+/-}$ & $p$ & \\
\hline$n$ & 41 & 43 & & 84 & 85 & & \\
\hline$\Delta V_{E}(\%)$ & $95(22)$ & $80(17)$ & 0.0011 & $29(19)^{* * * *}$ & $51(33)^{* * * *}$ & $<0.0001$ & $<0.0001$ \\
\hline$\Delta V_{\top}(\%)$ & $32(14)$ & $27(12)$ & NS & $13(13)^{* * * *}$ & $23(21)$ & 0.0004 & $<0.0009$ \\
\hline Peak- $V_{E}$ latency $(s)$ & $143(29)$ & $148(30)$ & NS & $99(41)^{* * * *}$ & $110(44)^{* * * *}$ & NS & NS \\
\hline \multicolumn{8}{|c|}{ HYPOXIC VENTILATORY DECLINE } \\
\hline$n$ & 41 & 43 & & 84 & 85 & & \\
\hline$\Delta V_{\mathrm{E}}(\%)$ & $-11(7)$ & $-7(9)$ & 0.0173 & $-33(12)^{* * * *}$ & $-25(18)^{* * * *}$ & 0.0007 & NS \\
\hline$\Delta V_{T}(\%)$ & $-12(10)$ & $-8(9)$ & NS & $-23(10)^{* * * *}$ & $-17(13)^{* * *}$ & 0.0021 & NS \\
\hline$\Delta T_{\text {TOT }}(\%)$ & $0(14)$ & $-1(14)$ & NS & $18(20)$ & $13(17)$ & NS & NS \\
\hline$\Delta V_{T}(\%)$ & $98(23)$ & $83(30)$ & 0.0300 & $81(30)^{* *}$ & $89(44)$ & NS & $<0.0314$ \\
\hline$\Delta T_{\text {TOT }}(\%)$ & $-19(12)$ & $-13(13)$ & 0.0346 & $-4(14)^{* * * *}$ & $-11(18)$ & 0.0440 & 0.0050 \\
\hline Peak- $V_{E}$ latency (s) & $294(65)$ & $292(59)$ & NS & $194(71)^{* * * *}$ & $250(90)^{*}$ & 0.0010 & 0.0129 \\
\hline
\end{tabular}

Values are percentage changes from pre-stimulus values. The peak-V $V_{E}$ response to hypoxia and hypoxic ventilatory decline were calculated individually over the entire 3 min of hypoxia and the 3-min post-hypoxic period, respectively. The peak-V $V_{E}$ response to hypercapnia was calculated over the entire 6 min of hypercapnia. Values indicate mean (SD) for each group. The p-value refers to the comparison between Phox $2 b^{+/+}$and Phox $2 b^{+/}$groups. Comparison of 33 versus $26^{\circ} \mathrm{C}$ for each genotype group; ${ }^{*} p<0.05 ;{ }^{*} p<0.01 ;{ }^{*} p<0.001 ;{ }^{*}{ }^{*} p<0.0001$. G $\times$ T: $p$-value for Genotype by Temperature interaction. Note that the $G \times T$ interaction was marginally significant for $V_{T}$.

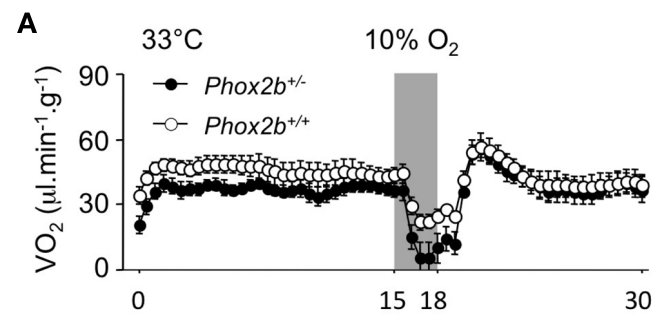

C

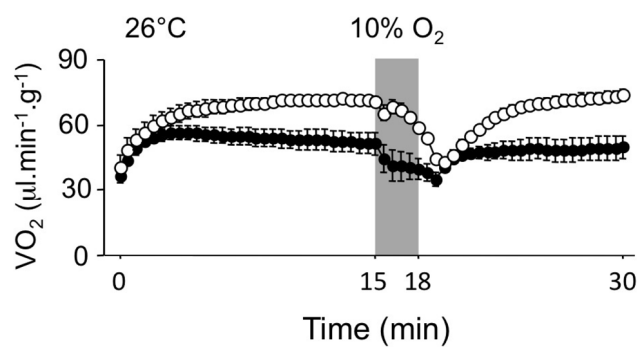

B

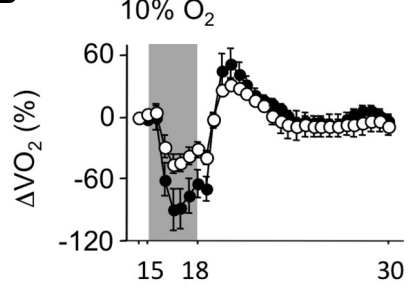

D

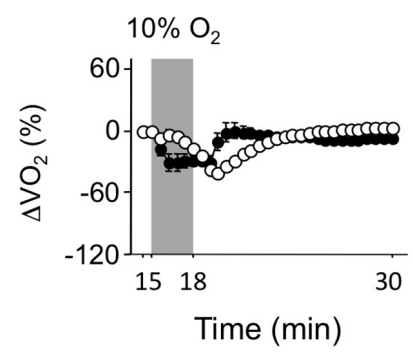

FIGURE 3 | Oxygen consumption $\left(\mathrm{VO}_{2}\right)$ in Phox $2 \mathrm{~b}^{+/+}$and $P$ hox $2 \mathrm{~b}^{+/-}$pups exposed to hypoxia $\left(10 \% \mathrm{O}_{2}\right.$, shaded) at $33^{\circ} \mathrm{C}\left[(\mathrm{A}, \mathrm{B})\right.$ Phox $2 b^{+/+}: n=8$ and

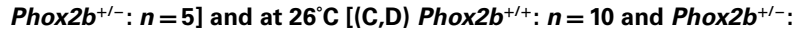
$\boldsymbol{n}=\mathbf{1 7}$ ). Values are absolute levels $(\mathbf{A}, \mathbf{C})$ and relative changes from pre-hypoxic levels $(\mathbf{B}, \mathbf{D})$. Regardless of temperature, hypoxia depresses $\mathrm{VO}_{2}$ in both genotype groups. At $33^{\circ} \mathrm{C}$, the drop in $\mathrm{VO}_{2}$ is larger in $P$ hox $2 \mathrm{~b}^{+/-}$pups. At $26^{\circ} \mathrm{C}$, the $\mathrm{VO}_{2}$ response to hypoxia is markedly altered in Phox $2 \mathrm{~b}^{+/-}$ compared to Phox $2 b^{+/+}$pups. Values indicate means \pm SEM for each group.

\section{IMPAIRED BRAIN 5-HT METABOLISM IN Phox $2 b^{+/-}$PUPS}

We found highly similar 5-HT levels in the two groups, although concentrations of $\mathrm{L}$ - Trp (a 5-HT precursor) and 5-HIAA (a 5-HT catabolite) were higher in Phox $2 b^{+/-}$preparations (Table 4). The 5-HT/5-HIAA ratio, a marker of 5-HT turnover rate, was significantly lower in Phox $2 b^{+/-}$preparations (Table 4). On the other 


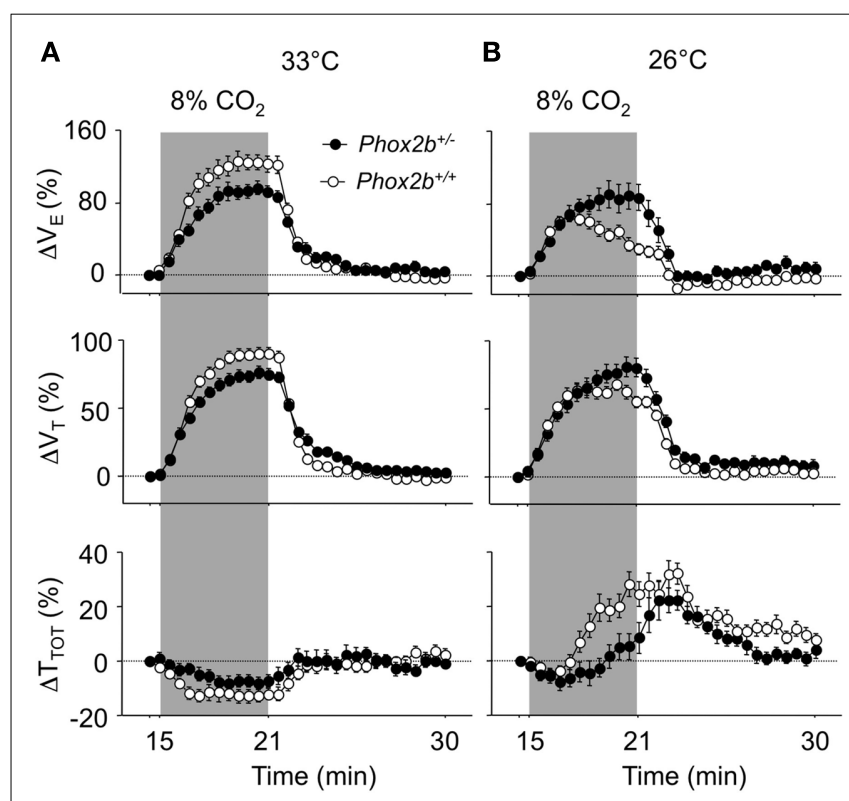

FIGURE 4 | Ventilatory responses to hypercapnia $\left(8 \% \mathrm{CO}_{2}\right.$, shaded) in Phox $2 b^{+/+}$and Phox $2 b^{+/-}$pups at $33^{\circ} \mathrm{C}$ (A) and $26^{\circ} \mathrm{C}$ (B). See legend of Figure 2 for abbreviations. At $33^{\circ} \mathrm{C}$, the $V_{E}$ response to hypercapnia was significantly lower in Phox $2 b^{+/-}$pups compared to Phox $2 b^{+/+}$pups. This difference was reversed at $26^{\circ} \mathrm{C}$, due to the lack of a hypercapnic ventilatory decline in $P h o \times 2 b^{+/-}$pups. Values indicate means \pm SEM for each group. See Table 1 for group sizes.

Table 4 | Detection of serotonin in the brains of 6-day-old Phox $2 b^{+/+}$ $(n=20)$ and Phox2b $b^{+/-}(n=13)$ pups.

\begin{tabular}{lccc}
\hline & Phox2 $^{+/+}$ & $\boldsymbol{P h o x 2}^{+/-}$ & $\boldsymbol{p}$-Value \\
\hline 5-HT & $5.73(1.45)$ & $6.41(1.49)$ & 0.0954 \\
I-Trp & $62.65(21.96)$ & $82.99(32.48)$ & 0.0196 \\
5-HIAA & $2.47(0.72)$ & $3.48(1.14)$ & 0.0019 \\
5-HT/5-HIAA & $2.48(0.84)$ & $1.96(0.54)$ & 0.0288 \\
\hline
\end{tabular}

Serotonin (5-HT), the serotonin precursor I-tryptophan (I-Trp), and its degradation product 5-hydroxyindoleacetic acid (5-HIAA) were quantified using HPLC. Data indicate abnormal 5-HT metabolism in Phox $2 b^{+/}$pups. Contents are expressed in nanogram per gram of wet brain tissue. Values indicate mean (SD) for each group.

hand, concentrations of adrenaline, dopamine and the metabolite DOPAC were very similar in Phox $2 b^{+/-}$and Phox $2 b^{+/+}$pups (data not shown).

\section{DISCUSSION}

The present results confirm and extend our previous findings regarding the impairment of respiratory control in Phox $2 b^{+l-}$ pups (Dauger et al., 2003; Ramanantsoa et al., 2006, 2007). Under thermoneutral conditions $\left(33^{\circ} \mathrm{C}\right), P h o x 2 b^{+/-}$pups show nearly normal baseline breathing patterns and a reduced ventilatory response to hypercapnia, and to a lesser extent, to hypoxia. More importantly, the present study reveals important impairments of the ventilatory and thermoregulatory responses to cold. In the cold, Phox $2 b^{+/-}$pups show reduced normoxic ventilation and oxygen consumption $\left(\mathrm{VO}_{2}\right)$ and a lower body temperature when compared to Phox $2 b^{+/+}$pups. Furthermore, the inhibitory effects of the cold on the ventilatory responses to hypoxia and hypercapnia are blunted in Phox $2 b^{+/-}$pups. Finally, these physiological impairments are associated with a modified turnover of brain 5-HT.

\section{IMPAIRED THERMOGENIC RESPONSES TO COLD}

The blunted $\mathrm{VO}_{2}$ and temperature responses to cold in Phox $2 b^{+/-}$ pups are novel findings that suggest that the phenotypic defects caused by Phox $2 b$ haploinsufficiency are more important than previously reported. In both genotype groups, body temperature progressively decreased in spite of constant high $\mathrm{VO}_{2}$ and $V_{\mathrm{E}}$ levels during exposure to cold. The increase in $\mathrm{VO}_{2}$ is due to the increase in oxidative metabolism caused by heat production by brown adipose tissue (Darnall et al., 2006). The thermogenic response to cold is a critical defensive response, present at birth (Frappell et al., 1998; Malik and Fewell, 2003) in numerous species (Maskrey, 1990; Cameron et al., 2000; Mortola, 2005) including mice (Bollen et al., 2009). Thus, Phox $2 b$ haploinsufficiency, which has a limited physiological impact under normal temperature conditions, may be of greater important under cold conditions. It is unclear whether these impairments are related to heat dissipation, which depends on the central control of vasomotricity and may rely on Phox $2 b$-dependent structures (Pattyn et al., 1999).

\section{CHEMOSENSITIVITY DISORDERS UNDER THERMONEUTRAL CONDITIONS}

Ventilatory results obtained in Phox $2 b^{+/-}$pups under thermoneutral conditions confirm previous observations carried out at similar ages (Dauger et al., 2003; Durand et al., 2005; Ramanantsoa et al., 2007). In air, $V_{\mathrm{E}}$ levels at $33^{\circ} \mathrm{C}$ were similar in $P h o x 2 b^{+/+}$ and Phox $2 b^{+/-}$pups; however, the $V_{\mathrm{E}}$ response to hypercapnia was blunted in Phox $2 b^{+/-}$pups, an effect previously shown to be present on postnatal day $2(\mathrm{P} 2)$, but recovered by around P10 (Dauger et al., 2003). In contrast, the slightly diminished responses to hypoxia under thermoneutral conditions, both in terms of the initial hyperpneic response and the HVD, are novel findings that contrast with the stronger HVD observed on P2 (Dauger et al., 2003). This difference is possibly due to the fact that the resetting of peripheral chemoreceptors occurs between 6 and $12 \mathrm{~h}$ postnatally in mice (Renolleau et al., 2001). Therefore, the hyperpneic response to hypoxia is very immature in 2-day-old pups, possibly masking the effects of the Phox $2 b$ mutation. The impairment of the hypoxic ventilatory response could thus be related to the previously described developmental defect in petrosal chemosensory neurons (Dauger et al., 2003).

VENTILATORY AND METABOLIC RESPONSES TO HYPOXIA IN THE COLD In both genotype groups, the $V_{\mathrm{E}}$ response to hypoxia was dramatically decreased by the cold, leading to a smaller initial hyperpneic component and to larger ventilatory decline, as previously reported (Bollen et al., 2009). In fact, the need for increased thermogenesis in the context of reduced oxygen availability induces a shift toward metabolic depression, rather than increased ventilation (Mortola, 2005). This depressive effect of the cold was 
reduced in Phox $2 b^{+-}$pups, as shown by their larger hyperpneic responses and smaller HVD when compared to Phox $2 b^{+/+}$ pups.

As a rule, numerous factors contribute to the HVD: decreased inputs from the carotid bodies, central inhibitory neurotransmitters, reduced $\mathrm{PaCO}_{2}$, decreased metabolism (Waters and Gozal, 2003). Among these, a defective metabolic response to hypoxia could account for the blunted HVD in Phox $2 b^{+/-}$pups. Not only was the overall $\mathrm{VO}_{2}$ response to the cold blunted in Phox $2 b^{+/-}$ pups, the decrease in $\mathrm{VO}_{2}$ caused by hypoxia presented major timedependent differences between Phox $2 b^{+/+}$and Phox $2 b^{+/-}$pups at both temperatures. Under thermoneutral conditions, the drop in $\mathrm{VO}_{2}$ was greater in Phox $2 b^{+/-}$than in Phox $2 b^{+/+}$pups. In the cold, the time course of $\mathrm{VO}_{2}$ in Phox $2 b^{+/-}$and Phox $2 b^{+/+}$pups was practically in opposite-phase, reflecting metabolic responses that were qualitatively and quantitatively different in these two groups. Although the differences in $\mathrm{VO}_{2}$ probably affected the ventilatory response to hypoxia in the cold, it is unlikely that they fully accounted for these genotype-related differences, a conclusion supported by the respective time courses of $\mathrm{VO}_{2}$ and $V_{\mathrm{E}}$ (Figures 2 and 3). Although technical limitations precluded the simultaneous measurement of $V_{\mathrm{E}}$ and $\mathrm{VO}_{2}$, the qualitative differences between the $V_{\mathrm{E}}$ and $\mathrm{VO}_{2}$ responses to hypoxia in the cold and their estimated ratios suggest that the coupling between these two responses is markedly affected in Phox $2 b^{+/-}$ pups.

\section{IMPAIRED VENTILATORY RESPONSES TO HYPERCAPNIA}

The present study confirms that the ventilatory response to hypercapnia in Phox $2 b^{+/-}$pups is diminished, as previously reported (Dauger et al., 2003; Ramanantsoa et al., 2007). In Phox2 ${ }^{+/+}$pups only, the hyperpneic response to hypercapnia was depressed in the cold, as compared to thermoneutral conditions, in line with previous results in 2-day-old mice (Ramanantsoa et al., 2007) and 4- to 6-day-old rats (Saiki and Mortola, 1996). The main consequence of the depressive effect of the cold on the $V_{\mathrm{E}}$ response to hypercapnia was that the $V_{\mathrm{E}}$ of $P h o x 2 b^{+/+}$pups decreased after 3 min of hypercapnia, an effect that was not observed in Phox $2 b^{+/-}$ pups. Previous studies have reported that the expiratory duration increases slightly during sustained hypercapnia in 5-day-old rats under thermoneutral conditions, an effect ascribed to GABAergic mechanisms (Abu-Shaweesh et al., 1999). The mechanisms underlying the depressive effects of the cold on the ventilatory response to hypercapnia may be related to the fact that an increase in $V_{\mathrm{E}}$ would promote heat dissipation and a reduction in body temperature (Mortola, 2005). Thus, the abnormal metabolic response of Phox $2 b^{+/-}$pups in response to cold may at least partly account for their altered response to hypercapnia when compared to Phox $2 b^{+/+}$pups.

\section{THE ROLE OF 5-HT METABOLISM}

Chromatographic analysis indicates that $5-\mathrm{HT}$ metabolism is impaired in the brain of Phox $2 b^{+/-}$pups. Whereas 5-HT levels were similar in Phox $2 b^{+/-}$and Phox $2 b^{+/+}$pups, the concentrations of its precursor and catabolite were higher, and the 5-HT turnover rate lower, in Phox $2 b^{+/-}$preparations. The abnormal
5-HT metabolism revealed by these results might be ascribable to the impaired development of 5-HT neurons, since Phox $2 b$ is closely involved in the production of essential enzymes for catecholamine biosynthesis and the selection between a motoneuronal and a 5-HT neuronal fate in the embryonic central nervous system (Pattyn et al., 2003; Alenina et al., 2006; Coppola et al., 2010). However, it is unclear generation of 5-HT neurons was disrupted in circuits involved in thermoregulation and respiratory control. Because the present chromatographic data were collected in the whole brain, it is difficult to specifically associate $5-\mathrm{HT}$ metabolism disorders and physiological disorders in Phox $2 b^{+-}$pups.

However, the putative association between 5-HT metabolism and early respiratory control disorders in Phox $2 b^{+/-}$pups is in line with previous studies in newborn mice with a genetic impairment in 5-HT signaling. In particular, newborn transgenic mice lacking serotonergic neurons display severe apnea and mortality (Hodges et al., 2009). Transgenic mice lacking central 5-HT neurons ( $L m \times 1 b^{f / f / p}$ mice) show a 50\% reduction in the hypercapnic ventilatory response and insufficient heat production under cold conditions (Hodges and Richerson, 2008; Hodges et al., 2008). Adult Pet-1 null mice, which retain $30 \%$ of their central 5-HT neurons, show gender-related impairments in baseline ventilation, hypercapnic ventilatory responses, and heat production in response to cold (Hodges et al., 2011). Taken together, these studies strongly support the idea that 5 - $\mathrm{HT}$ neurons play an integrative role in the control of ventilation in response to metabolic and thermoregulatory demands, as previously proposed (reviewed in Hodges et al., 2011). Therefore, the impairment of 5-HT metabolism in Phox $2 b^{+-}$pups may account for their reduced ventilatory drive and disrupted hypoxic hypometabolism response to cold.

\section{CLINICAL IMPLICATIONS}

The present study suggests that Phox $2 b$ haploinsufficiency compromises the newborn's ability to cope with hypoxia and cold. Hypoxia is the most common cause of brain damage in newborns, and hypothermia is also associated with increased morbidity and mortality, although moderate hypothermia may be neuroprotective in infants with hypoxic-ischemic encephalopathy (Johnston et al., 2011). To date, the only known link between Phox $2 b$ mutations and physiological disorders concerns CCHS. However, the disease-causing mechanism of CCHS is not Phox $2 b$ haploinsufficiency (i.e., the putative consequence of the invalidation of one allele of Phox $2 b$ ) but rather a toxic gain of function or a dominant-negative effect of a Phox $2 b$ polyalanine expansion (Amiel et al., 2009), which causes a much more severe phenotype than Phox $2 b$ haploinsufficiency. The analysis of the parents and family members of CCHS patients (5-10\% of CCHS mutations are inherited) has revealed milder forms of CCHS than previously identified, generally due to shorter polyalanine expansions or non-polyalanine $\mathrm{PHOX} 2 \mathrm{~B}$ mutations (Weese-Mayer et al., 2010). These subclinical phenotypes suggest that $P H O X 2 B$ mutations may induce more frequent and less severe autonomic dysregulations than those observed in CCHS. In this respect, our present results indicate that Phox $2 b$ mutations with mild consequences under normal conditions 
could nevertheless profoundly alter the physiological response to extreme conditions.

\section{CONCLUSION}

In the present study, we show that the cold markedly alters the respiratory phenotype of Phox $2 b^{+/-}$pups, as reflected by their impaired baseline ventilation and ventilatory responses to hypercapnia and hypoxia. The ventilatory impairments seen in Phox $2 b^{+/-}$pups were at least partially accounted for by their reduced ability to induce thermogenic responses to cold. Thus Phox $2 b$ haploinsufficiency, which has mild effects on vital functions under standard conditions, may in fact profoundly alter

\section{REFERENCES}

Abbott, S. B., Stornetta, R. L., Fortuna, M. G., Depuy, S. D., West, G. H., Harris, T. E., and Guyenet, P. G. (2009). Photostimulation of retrotrapezoid nucleus phox $2 b-$ expressing neurons in vivo produces long-lasting activation of breathing in rats. J. Neurosci. 29, 5806-5819.

Abu-Shaweesh, J. M., Dreshaj, I. A., Thomas, A. J., Haxhiu, M. A., Strohl, K. P., and Martin, R. J. (1999). Changes in respiratory timing induced by hypercapnia in maturing rats. J. Appl. Physiol. 87, 484-490.

Alenina, N., Bashammakh, S., and Bader, M. (2006). Specification and differentiation of serotonergic neurons. Stem Cell Rev. 2, 5-10.

Amiel, J., Dubreuil, V., Ramanantsoa, N., Fortin, G., Gallego, J., Brunet, J. F., and Goridis, C. (2009). PHOX2B in respiratory control: lessons from congenital central hypoventilation syndrome and its mouse models. Respir. Physiol. Neurobiol. 168, 125-132.

Bollen, B., Bouslama, M., Matrot, B., Rotrou, Y., Vardon, G., Lofaso, F., Van den Bergh, O., D'Hooge, R., and Gallego, J. (2009). Cold stimulates the behavioral response to hypoxia in newborn mice. Am. J. Physiol. Regul. Integr. Comp. Physiol. 296, R1503-R1511.

Cameron, Y. L., Merazzi, D., and Mortola, J. P. (2000). Variability of the breathing pattern in newborn rats: effects of ambient temperature in normoxia or hypoxia. Pediatr. Res. 47, 813-818.

Chardon, K., Bach, V., Telliez, F., Cardot, V., Tourneux, P., Leke, A., and Libert, J. P. (2004). Effect of caffeine on peripheral chemoreceptor activity in premature neonates: interaction with sleep stages. J. Appl. Physiol. 96, 2161-2166.

Coles, S. K., and Dick, T. E. (1996). Neurones in the ventrolateral pons are required for post-hypoxic frequency decline in rats. J. Physiol. 497(Pt 1), 79-94.

Coppola, E., d'Autreaux, F., Rijli, F. M., and Brunet, J. F. (2010). Ongoing roles of Phox 2 homeodomain transcription factors during neuronal differentiation. Development 137, 4211-4220.

Darnall, R. A., Ariagno, R. L., and Kinney, H. C. (2006). The late preterm infant and the control of breathing, sleep, and brainstem development: a review. Clin. Perinatol. 33, 883-914; abstract $\mathrm{x}$.

Dauger, S., Pattyn, A., Lofaso, F., Gaultier, C., Goridis, C., Gallego, J., and Brunet, J. F. (2003). Phox $2 b$ controls the development of peripheral chemoreceptors and afferent visceral pathways. Development 130 , 6635-6642.

Dubreuil, V., Ramanantsoa, N., Trochet, D., Vaubourg, V., Amiel, J., Gallego, J., Brunet, J. F., and Goridis, C. (2008). A human mutation in Phox $2 \mathrm{~b}$ causes lack of $\mathrm{CO} 2$ chemosensitivity, fatal central apnea, and specific loss of parafacial neurons. Proc. Natl. Acad. Sci. U.S.A. 105, 1067-1072.

Dubreuil, V., Thoby-Brisson, M., Rallu, M., Persson, K., Pattyn, A., Birchmeier, C., Brunet, J. F., Fortin, G., and Goridis, C. (2009). Defective respiratory rhythmogenesis and loss of central chemosensitivity in Phox $2 b$ mutants targeting retrotrapezoid nucleus neurons. J. Neurosci. 29, 14836-14846.

Durand, E., Dauger, S., Pattyn, A., Gaultier, C., Goridis, C., and Gallego, J. (2005). Sleep-disordered breathing in newborn mice heterozygous for the transcription factor Phox $2 b$. Am. J. Respir. Crit. Care Med. 172, 238-243.

Enhorning, G., van Schaik, S., Lundgren, C., and Vargas, I. (1998). Wholebody plethysmography, does it measure tidal volume of small animals? Can. J. Physiol. Pharmacol. 76, 945-951.

Frappell, P. B., Dotta, A., and Mortola, J. P. (1992). Metabolism during

the ability to cope with severe metabolic challenges during early postnatal development.

\section{ACKNOWLEDGMENTS}

We are greatly indebted to Dr. Jean-François Brunet and Dr. Christo Goridis for extensive advice and valuable discussions throughout the project and to Thomas Bourgeois for his contribution to experimental work. Grants: This study was supported by the Institute National de la Santé et de la Recherche Médicale (INSERM), Society de Pneumologie de Langue Française (SPLF), Association Française du Syndrome d'Ondine (AFSO), and Centre National de la Recherche Scientifique (CNRS).

normoxia, hyperoxia, and recovery in newborn rats. Can. J. Physiol. Pharmacol. 70, 408-411.

Frappell, P. B., Leon-Velarde, F., Aguero, L., and Mortola, J. P. (1998). Response to cooling temperature in infants born at an altitude of 4,330 meters. Am. J. Respir. Crit. Care Med. 158, 1751-1756

Gargaglioni, L. H., Steiner, A. A. and Branco, L. G. (2005). Involvement of serotoninergic receptors in the anteroventral preoptic region on hypoxia-induced hypothermia. Brain Res. 1044, 16-24.

Gautier, H. (1996). Interactions among metabolic rate, hypoxia, and control of breathing. J. Appl. Physiol. 81, 521-527.

Goridis, C., Dubreuil, V., ThobyBrisson, M., Fortin, G., and Brunet, J. F. (2010). Phox 2 b, congenital central hypoventilation syndrome and the control of respiration. Semin. Cell Dev. Biol. 21, 814-822.

Hagberg, H., Peebles, D., and Mallard, C. (2002). Models of white matter injury: comparison of infectious, hypoxic-ischemic, and excitotoxic insults. Ment. Retard Dev. Disabil. Res. Rev. 8, 30-38.

Hilaire, G., Voituron, N., Menuet, C. Ichiyama, R. M., Subramanian, H. H., and Dutschmann, M. (2010). The role of serotonin in respiratory function and dysfunction. Respir. Physiol. Neurobiol. 174, 76-88.

Hodges, M. R., Best, S., and Richerson, G. B. (2011). Altered ventilatory and thermoregulatory control in male and female adult Pet-1 null mice. Respir. Physiol. Neurobiol. 177 133-140.

Hodges, M. R., and Richerson, G. B. (2008). Interaction between defects in ventilatory and thermoregulatory control in mice lacking 5-HT neurons. Respir. Physiol. Neurobiol. 164, 350-357.

Hodges, M. R., and Richerson, G. B. (2010). The role of medullary serotonin (5-HT) neurons in respiratory control: contributions to eupneic ventilation, $\mathrm{CO} 2$ chemoreception, and thermoregulation. J. Appl. Phys iol. 108, 1425-1432.

Hodges, M. R., Tattersall, G. J., Harris, M. B., McEvoy, S. D., Richerson, D. N., Deneris, E. S., Johnson, R. L., Chen, Z. F., and Richerson, G. B. (2008). Defects in breathing and thermoregulation in mice with near-complete absence of central serotonin neurons. J. Neurosci. 28, 2495-2505.

Hodges, M. R., Wehner, M., Aungst, J., Smith, J. C., and Richerson, G. B. (2009). Transgenic mice lacking serotonin neurons have severe apnea and high mortality during development. J. Neurosci. 29, 10341-10349.

Jacob, J., Ferri, A. L., Milton, C., Prin, F., Pla, P., Lin, W., Gavalas, A., Ang, S. L., and Briscoe, J. (2007). Transcriptional repression coordinates the temporal switch from motor to serotonergic neurogenesis. Nat. Neurosci. 10, 1433-1439.

Johnston, M. V., Fatemi, A., Wilson, M. A., and Northington, F. (2011). Treatment advances in neonatal neuroprotection and neurointensive care. Lancet Neurol. 10, 372-382.

Lofaso, F., Dauger, S., Matrot, B., Vardon, G., Gaultier, C., and Gallego, J. (2007). Inhibitory effects of repeated hyperoxia on breathing in newborn mice. Eur. Respir. J. 29, 18-24.

Madden, C. J., and Morrison, S. F. (2010). Endogenous activation of spinal 5-hydroxytryptamine (5-HT) receptors contributes to the thermoregulatory activation of brown adipose tissue. Am. J. Physiol. Regul. Integr. Comp. Physiol. 298, R776R783.

Malik, S. S., and Fewell, J. E. (2003). Thermoregulation in rats during early postnatal maturation: importance of nitric oxide. Am. J. Physiol. Regul. Integr. Comp. Physiol. 285, R1366-R1372.

Maskrey, M. (1990). Body temperature effects on hypoxic and hypercapnic responses in awake rats. Am. J. Physiol. 259, R492-R498. 
Mortola, J. P. (1999). How newborn mammals cope with hypoxia. Respir. Physiol. 116, 95-103.

Mortola, J. P. (2005). Influence of temperature on metabolism and breathing during mammalian ontogenesis. Respir. Physiol. Neurobiol. 149, 155-164.

Mortola, J. P., and Frappell, P. B. (1998). On the barometric method for measurements of ventilation, and its use in small animals. Can. J. Physiol. Pharmacol. 76, 937-944.

Mortola, J. P., and Gautier, H. (1995). "Interaction between metabolism and ventilaton: effects of respiratory gases and temperature," in Regulation of Breathing, eds J. A. Dempsey and A. I. Pack (New York: Marcel Dekker), 1011-1064.

Osaka, T. (2010). Hypoxia-induced hypothermia mediated by noradrenaline and nitric oxide in the rostromedial preoptic area. Neuroscience 165, 976-983.

Pattyn, A., Morin, X., Cremer, H., Goridis, C., and Brunet, J. F. (1999). The homeobox gene Phox $2 b$ is essential for the development of autonomic neural crest derivatives. Nature 399, 366-370.

Pattyn, A., Vallstedt, A., Dias, J. M., Samad, O. A., Krumlauf, R., Rijli, F. M., Brunet, J. F., and Ericson,
J. (2003). Coordinated temporal and spatial control of motor neuron and serotonergic neuron generation from a common pool of CNS progenitors. Genes Dev. 17, 729-737.

Putnam, R. W., Conrad, S. C., Gdovin M. J., Erlichman, J. S., and Leiter, J. C. (2005). Neonatal maturation of the hypercapnic ventilatory response and central neural CO 2 chemosensitivity. Respir. Physiol. Neurobiol. 149, 165-179.

Ramanantsoa, N., Vaubourg, V., Dauger, S., Matrot, B., Vardon, G., Chettouh, Z., Gaultier, C., Goridis, C., and Gallego, J. (2006). Ventilatory response to hyperoxia in newborn mice heterozygous for the transcription factor Phox2b. Am. J. Physiol. Regul. Integr. Comp. Physiol. 290, R1691-R1696.

Ramanantsoa, N., Vaubourg, V., Matrot, B., Vardon, G., Dauger, S., and Gallego, J. (2007). Effects of temperature on ventilatory response to hypercapnia in newborn mice heterozygous for transcription factor Phox2b. Am. J. Physiol. Regul. Integr. Comp. Physiol. 293, R2027-R2035.

Ramirez, J. M., and Viemari, J. C. (2005). Determinants of inspiratory activity. Respir. Physiol. Neurobiol. 147, 145-157.
Renolleau, S., Dauger, S., Autret, F. Vardon, G., Gaultier, C., and Gallego, J. (2001). Maturation of baseline breathing and of hypercapnic and hypoxic ventilatory responses in newborn mice. Am. J. Physiol. Regul. Integr. Comp. Physiol. 281, R1746-R1753.

Saiki, C., and Mortola, J. P. (1996). Effect of $\mathrm{CO} 2$ on the metabolic and ventilatory responses to ambient temperature in conscious adult and newborn rats. J. Physiol. 491(Pt 1), 261-269.

Sawnani, H., Jackson, T., Murphy, T., Beckerman, R., and Simakajornboon, N. (2004). The effect of maternal smoking on respiratory and arousal patterns in preterm infants during sleep. Am. J. Respir. Crit. Care Med. 169, 733-738.

Steiner, A. A., and Branco, L. G. (2002). Hypoxia-induced anapyrexia: implications and putative mediators. Annu. Rev. Physiol. 64, 263-288.

Waters, K. A., and Gozal, D. (2003). Responses to hypoxia during early development. Respir. Physiol. Neurobiol. 136, 115-129.

Weese-Mayer, D. E., Berry-Kravis, E. M. Ceccherini, I., Keens, T. G., Loghmanee, D. A., and Trang, H. (2010). An official ATS clinical policy statement: congenital central hypoventilation syndrome: genetic basis, diagnosis, and management. Am. J. Respir. Crit. Care Med. 181, 626-644.

Conflict of Interest Statement: The authors declare that the research was conducted in the absence of any commercial or financial relationships that could be construed as a potential conflict of interest.

Received: 06 July 2011; accepted: 30 August 2011; published online: 23 September 2011.

Citation: Ramanantsoa N, Matrot B, Vardon $G$, Lajard A-M, Voituron $N$, Dauger S, Denjean A, Hilaire G and Gallego $J$ (2011) Impaired ventilatory and thermoregulatory responses to hypoxic stress in newborn Phox $2 b$ heterozygous knock-out mice. Front. Physio. 2:61. doi: 10.3389/fphys.2011.00061

This article was submitted to Frontiers in Respiratory Physiology, a specialty of Frontiers in Physiology.

Copyright (C) 2011 Ramanantsoa, Matrot, Vardon, Lajard, Voituron, Dauger, Denjean, Hilaire and Gallego. This is an open-access article subject to a non-exclusive license between the authors and Frontiers Media SA, which permits use, distribution and reproduction in other forums, provided the original authors and source are credited and other Frontiers conditions are complied with. 